01786 YPEROXIC LUNG INUURY: PULMONARY PROSTAGLANDIN (PG) INCREASES PRECEDE MORPHOLOGIC CHANGES. Joseph R. Lauren Pachman, and carl E. Hunt. Northwestern Uúniversity. Departments of Pediatrics and Medicine, Chicago, IL.

To assess the role of PGs in the early development of hyperoxic lung injury, 11 adult rabbits with chronically implanted arterial and venous catheters were exposed to $>958 \mathrm{O}_{2}$ or air for 24 hours. At 24 hours, $\mathrm{PaO}_{2}$ was $524 \pm 41$ (SD) and $92 \pm 10$ Torr in the hyperoxic and control rabbits. PG $E_{2}, P G 6$-keto $F_{1} \propto$ and thromboxane (TX) $B_{2}$ levels (pg/mi) were measured by RIA in plasma and in bronchoalveolar lavage (BAL) supernatant. Protein (P) was measured in serum and BAL; BAL WBC and 8 PMN were also measured. Hyperoxic exposure for only 24 hours did not cause a significant increase in BAL P (Table, Mean \pm SD) or any light

\begin{tabular}{|c|c|c|c|c|c|}
\hline \multirow{2}{*}{ GROUP } & \multirow{2}{*}{$\begin{array}{c}\text { BAL } \\
\text { PMN }(8)\end{array}$} & \multirow{2}{*}{$\begin{array}{c}\overline{B A L} \bar{P} \\
(\mathrm{ug} / \mathrm{ml})\end{array}$} & \multicolumn{3}{|c|}{ BAL:Plasma (pg/ml) } \\
\hline & & & & PG 6-keto $F_{1} \propto$ & \\
\hline & $0.6 \pm 0$. & $60 \pm 30$ & & & 0.6 \\
\hline & $\begin{array}{r}3.6 \pm 1 . \\
<.05\end{array}$ & $\begin{array}{c}90 \pm \\
\text { NS }\end{array}$ & $\begin{array}{c}1.5 \pm 1 \\
\text { NS }\end{array}$ & $\begin{array}{c}.0 \pm 0 \\
.025\end{array}$ & NS \\
\hline
\end{tabular}

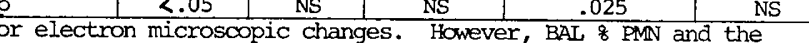
BAL:plasma PG 6-keto $\mathrm{F}_{1} \propto$ ratio both increased significantly. The increases in BAL:plasma $P G E_{2}$ and TX $B_{2}$ were not significant. In sumary, increased PG 6-keto $F_{1} \alpha$ may be an early marker of hyperoxic lung injury. In addition to providing further support for a relationship between PGs and the development of hyperoxic lung injury, these results suggest a potential preventive role for PG inhibitors.

SURFACE ACTIVE MATERIAL (SAM) AND COMPLIANCE CHANGes DURING RECOVERY FROM EXPERIMEMTAL HYALINE MEMBRANE DURING RECOVERY FROM EXPERIMEQYTAL HYALINE MEMBRANE
DISEASE (HMD) DISEASE (HMD) J.C. Jackson, S. Palmer, T.A.
Standaert, J. Murphy, W.E. Truog, D.E. Woodrum, R.J. Badura, G.K. Sorensen, J.F. Watchko, W.A.

It is not known whether recovery from HMD begins in spite of a deficiency of SAM or only after return to some critical value. Eight of $12 \mathrm{M}$. nemestrina primates delivered at $80 \%$ of normal gestation developed HMD and were sacrificed at defined stages in their recovery. Postmortem deflation stability (\% total lung capacity [TLC] at $\mathrm{P}=10 \mathrm{~cm} \mathrm{H}_{2} \mathrm{O}$ pressure) and diphosphatidylcholine (DPC) quantities in unlavaged lung tissue and in bronchoalveolar lavage were compared to controls as well as four healthy term 3-4 week old infants.

$\begin{array}{llc}\% \text { TLC at } & \text { T1ssue DPC } & \text { Lavage DPC } \\ \mathrm{P}=10 & \text { mg/gm dry lung } & \text { mg/gm dry 1ung } \\ 57.3 \pm 11.0 & 15.0 \pm 3.5 & 0.59 \pm 0.28 \\ 82.0 \pm 2.8 & 15.9 & 2.2 \\ 85.7 \pm 3.1 & 30.4 \pm 4.0 & 10.2 \pm 3.2 \\ 87.8 \pm 5.4 & 29.7 \pm 4.6 & 15.0 \pm 8.9 \\ 78.0 \pm 5.0 & 18.0 \pm 1.3 & 2.9 \pm 0.48\end{array}$

HMD no recovery

HMD early recovery

MMD late recovery

$3-4$ wk o1d term

$78.0 \pm 5.0$

$18.0 \pm 1.3$

$2.9 \pm 0.48$

We conclude that 1) the dlsparity between tissue and lavage DPC quantities in animals with HMD suggests a problem in release of SAM rather than tissue production and 2) clinical recovery and improvement in deflation stability occur despite DPC levels that are quite low compared to control but simflar to older infants. ( Supported by NIH\#HL19187 and \#RRO0166, Fellow of American Lung Association)

REUTILIZATION (RU) OF SURFACTANT (NS) PHOSPHATIDYL-

1788 CHOLINE (PC) IN ADULT RABBITS (R). H.C. Jacobs, M. Ikegami, A.H. Jobe, D. Berry, Dept. of Pediatrics, arbor-UCLA Medical Center, UCLA School of Medicine, Torrance, CA Several studies have demonstrated RU of NS PC in developing and aduit $R$. The magnitude of $R U$ in adult $R$ has not been determined. We injected $871 \mathrm{~kg} \mathrm{R}$ with two solutions simultaneously. mined. We injected $87 \mathrm{lg} R$ with two solutions simultaneously. NS plus [ ${ }^{32}$ P]dipalmitoylPC (DPC) was injected intratracheally (IT). R were sacrificed from $10 \mathrm{~min}$ to $72 \mathrm{hrs}$ after injection. From each $R$ we collected a complete alveolar wash (AW) and isolated a lamellar body (LB) fraction. We measured total $\left[{ }^{3} \mathrm{H}\right] \mathrm{PC}$ and $\left[{ }^{3} \mathrm{P}\right] \mathrm{PC}$ recovered in the $A W$ and $\left[{ }^{1{ }^{4}} \mathrm{C}\right] \mathrm{PC}$ specific activity $(S A)$ in the AW and in $L B$. From curves of $\left[{ }^{14} C\right] P C S A$ in the $L B$ and the AW vs time, we calculated the flux of $P C$ from the $L B$ into the AW (PC flux) and the turnover times ( $T t$ ) for alveolar $P C$ ( $T t$ =total AW $P C / P C$ flux). A computer generated equation describing the total AW $\left[{ }^{3} \mathrm{H}\right] \mathrm{PC}$ vs time was obtained and used to independently calculate the PC flux, the Tt, the \% RU of NS PC and the LB PC pool size. The results are shown in the table.

\section{IV $\frac{T_{t}}{88}$ PC Flux $\%$ RU Total LB PC/Total AW PC IT $\quad 6.18 \mathrm{~h} \quad 1.82 \mu \mathrm{mol} \mathrm{PC} / \mathrm{h} \quad \overline{31 \%} \quad \overline{--}$} Also, the ratio of $\left[{ }^{3} \mathrm{H}\right] \mathrm{PC}$ to $\left[{ }^{32} \mathrm{P}\right] \mathrm{PC}$ in the Aw did not change with time. We concluded that 1) IT and IV labeling gave comparable results. 2) IT NS and the added DPC behaved metabolically like endogenous NS. 3) That RU of PC in adult $R(37 \%)$ is less than that of developing $\mathrm{R}(>90 \%)$.
1789 SEQUENTIAL CHANGES IN ALVEOLAR-CAPILLARY MEMBRANE 9 P. Jefferies, Geoffrey Coates, (spon. by J.C. Sinclair) McMaster University, Depts. Of Pediarics and Radiology, Hamilton, Ontario, Canada $L 8 N 3 Z 5$

Because HMD is complicated by increased lung water and protein content, a Iveolar-capill ary membrane permeability may be increased. Usina aerosolized $99 m$ technetium-diethylene triamine penta acetate (TC-DTPA) as previously described (ARRD 127(4):299, 1983), we assessed pulmonary epithelial permeability on 28 occasions in 13 intubated infants, 28 to 36 weeks gestation, with HMD. The lungs were insufflated with 10-15 $\mathrm{MC} i$ of TC-DTPA and counts over the upper right chest recorded for 30 minutes with a NaI scintillation probe. Pulmonary half-life $\left(T_{1}^{1} / 2\right)$ of Tc-DTPA was calculated from the slope of the clearance curve. Infants were studied as soon after intubation as possible and 2-3 times subsequently until extubation. In a 1111 studies done within 72 hours of birth, the clearance curve was biphasic with a rapid phase $T \frac{1}{2}$ of $1.6 \pm 0.2$ min (mean $\pm \mathrm{SE}$ ). Normal adults have a monophasic curve with $T \frac{1}{2}$ of $45-80$ minutes. In 7 of the 9 studies done just prior to extubation on infants who recovered (mean age 6 days) the curve had changed to monophasic with $T_{1}^{\frac{1}{2}}$ of $48.1 \pm 8.0 \mathrm{~min}$. Two infants remained $0_{2}$ and ventilator dependent and had persistent

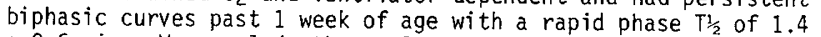
$\pm 0.6 \mathrm{~min}$. We conclude that puImonary clearance of TC-OTPA in infants with HMD in the first 3 days of life is rapid, suggesting increased permeability to small solutes, and as HMD resolves, permeability approaches normal adult values. Persistent lung disease is associated with persistent rapid clearance.
1790 INCREASED LUNG PROTEIN PERMEABILITY OF PREMATURELY DELIVERED AND VENTILATED LAMBS. A.H. Jobe M. Ikegami, H.C. Jacobs, D. Berry, Dept. of Pediatrics, Harbor-UCLA Medical Center, UCLA School of Medicine, Torrance, $C A$.

Groups of 8 lambs were delivered at 122, 135 or 146 days (d) gestational age (GA) and ventilated. Lambs at $122 \mathrm{~d}$ were treated with natural sheep surfactant (NS). Mean blood gas values and ventilator settings were similar for all groups. The lambs at $146 \mathrm{~d}$ required lower peak inspiratory pressures (PIP) to normalize $\mathrm{pCO}_{2}$ values relative to the other lambs (15 vs $24 \mathrm{~cm} \mathrm{H} \mathrm{H}_{2}$ ) . To control for this variable, 4 lambs at $146 \mathrm{~d}$ were ventilated at $25 \mathrm{~cm} \mathrm{H} \mathrm{H}_{2} \mathrm{O}$ PIP with added $\mathrm{CO}_{2}$ to normal ize $\mathrm{pCO}_{2}$. The exit from the airways of ${ }^{125} \mathrm{I}$-albumin added to fetal lung fluid at delivery, the entrance into the airways of ${ }^{131} I$-albumin given by vascular injection, the protein in alveolar washes (AW), and \% recovery of labeled albumin in lung tissue (corrected for blood volume) were measured after $3 \mathrm{hr}$ of ventilation.

125 I-albumin

${ }^{131} \mathrm{I}$-albumin

Mg Protein AW $/ \mathrm{kg}$ $\%$ Recovery of Injected Dose in AW (M+SE)

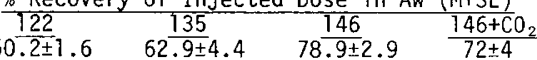
$\begin{array}{lrrr} & & \\ 3.3 \pm 4 & 2.9 \pm 4.4 & 78.9 \pm 2.9 & 72 \pm 4 \\ 1.30 \pm 4 & 2.3 \pm 0.3 & 0.6 \pm 0.1 & 0.7 \pm 0.1\end{array}$ $\begin{array}{llll}3.3 \pm 4 & 2.3 \pm 0.3 & 0.6 \pm 0.1 & 0.7 \pm 0.1\end{array}$ The amount of ${ }^{125}$ I that left the alveoli increased, the amount of that entered the alveol $i$ increased, and total protein increased as GA decreased ( $p$ values $<0.05$, ANOVA). There is an increasing protein leak with decreasing GA in ventilated lambs that is independent of NS treatment or the PIP required to ventilate the lambs.

TIMS OF HIGH FREQUENCY JET VENTILATION IN SMALL SUB 1791 JECTS. Martin Keszler, Blanca Molina, K.N. SivaSubra 1 manian, (Spon. by P.L. Calcaano). Dept. of Pediatrics To define limits of injector size/internal compressible volume (ICV) of the jet tubing in small subjects, we studied anesthetized paralyzed cats using the MK- 800 jet ventilator \& noncompliant tubing with ICV of $14 \mathrm{ml}$. FIO2 of 1.0 \& $30 \%$ duty cycle remained constant. In part I the injector size was varied from \#12,14,16 to 12 (2.16-1.06mm) at rates of $150 \& 300 / \mathrm{min}$ vit th norma 7 and noncornp 7 iant lungs. The driving pressure was adjusted to keep a constant mean airway pressure (MAP) for each set of conditions. In part II the ICV was $\uparrow$ from baseline(B) to $1.5 B, 2 B$ and $3 B$ through the same sequence as in part I, using \#14 \&\#16 injectors. Tracheal pressure tracing was recorded. Despite constant MAP, $\mathrm{PCO}_{2}$ rose with + injector diameter though with normat lungs at $150 / \mathrm{min} \mathrm{PCO}_{2}$ was normal even with the smallest injector (\#18). Increasing ICV up to $3 B$ had no effect with \#14 injector or with normal lungs. With

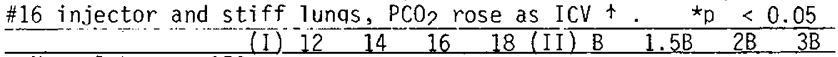

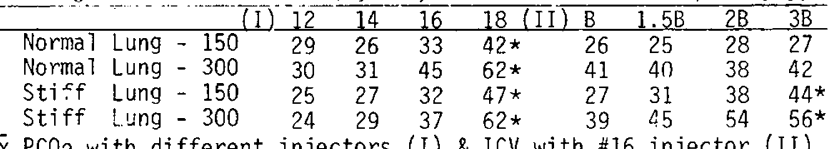

$\mathrm{PCO} 2$ with different injectors (I) \& ICV with \#16 injector (II) When an unfavorable relationship exists between injector size, driving pressure \& ICV excessive compression of gas in the patient circuit results in loss of pulsatility of aas flow $\&$ inadvertent PEEP leading to $\mathrm{CO}_{2}$ retention. 